Thorax (1965), 20, 495.

\title{
Homograft valve replacement for aortic valve disease
}

\author{
B. G. B A R R A T T-BOYES, J. B. LOWE, D. S. COLE, AN D \\ D. T. K E L L Y
}

From the Cardio-thoracic Surgical Unit, Green Lane Hospital, Auckland, New Zealand

Our experience with homograft replacement of the aortic valve now includes 175 patients operated on over a period of almost three years, and we have come to accept this method as the best surgical treatment for aortic incompetence and for calcific aortic stenosis.

As others continue to use a ball valve prosthesis, it is important to analyse the results with the homograft valve, paying particular attention to the follow-up period. All patients operated on in this way during the first two years from the inception of this technique in August 1962 have therefore been reviewed: with two exceptions, all survivors have been followed from four to 28 months from the time of operation. Post-operative cardiac catheterization has been performed in ?1 patients operated on early in the series. The first 44 patients were included in an earlier account of this subject (Barratt-Boyes, 1964).

\section{CLINICAL MATERIAL}

The present series comprises 101 patients, 52 with dominant aortic incompetence and 49 with calcific aortic stenosis.

In the incompetence group, 11 patients had also mild to moderate stenosis; seven of these valves were fairly heavily calcified, and four had ascending aortic arch aneurysms which were excised at the same operation (two due to a localized thoracic dissection and two syphilitic). Ten patients had mitral valve disease requiring surgical attention (five had stenosis and five incompetence), and one of these had severe tricuspid incompetence in addition.

In the stenotic group, many had associated aortic diastolic murmurs, but in only four was incompetence significant, and one further patient had mitral stenosis. All the aortic valves in this group were calcified and were not suitable for simple valvotomy or sculpturing, and many were bicuspid. In one patient there was an additional severe supravalvular aortic stenosis which required a large elliptical teflon insert for its relief, and it was necessary to suture the homograft valve to teflon at this point.

Other associated lesions were recognized in 54 of the 101 patients. Coronary artery disease was not considered a contra-indication to operation, provided the aortic valve disease was also severe. It was probably present in eight patients in the stenotic group, where there was a convincing history of previous myocardial infarction, and possibly also in many others, including five patients with a complete bundle branch block and one with an intermittent complete heart block. One 45-year-old woman with moderate aortic incompetence and complete left bundle branch block had a history of severe angina of effort from the age of 14 years: angiocardiography had demonstrated complete occlusion of the left coronary artery origin which was confirmed at operation. Essential hypertension was a prominent feature in the histories of two patients with aortic stenosis and two with incompetence. In one of the latter, uncontrollable congestive heart failure was present, and the incompetence was moderate rather than severe. In addition to severe aortic valve disease one patient had coarctation of the aorta, and another had an abdominal aortic aneurysm. Impaired renal function was noted in 15 patients, with a blood urea above $100 \mathrm{mg}$./ $100 \mathrm{ml}$. in several: in some, chronic severe congestive heart failure may have been the prime cause of the renal derangement and high blood urea. However, no patient was refused operation because of reduced renal function. Other conditions included diabetes in two patients, thyrotoxicosis in one, and myxoedema in one.

Cardiac surgery had been performed previously in six patients. Five of these had had aortic valve surgery (two had decalcification and three insertion of artificial leaflets) and one a closed mitral valvotomy. 
TABLE I

PRE-OPERATIVE SYMPTOMS

\begin{tabular}{cc|c|c|c|c}
\hline \multicolumn{1}{c|}{ Valve Lesion } & & \multicolumn{3}{|c|}{ Symptoms } & Total \\
\cline { 3 - 6 } & & Grade 2 & Grade 3 & Grade 4 & \\
\hline Aortic incompetence only &. & 9 & 4 & 29 & 42 \\
Aortic stenosis only . & $\ldots$ & 3 & 21 & 24 & 48 \\
Multivalvular disease &. & 0 & 0 & 11 & 11 \\
\hline Total . . . &. & 12 & 25 & 64 & 101 \\
\hline
\end{tabular}

Symptoms have been graded 1 to 4 with the numbers in each grade detailed in Table I. There were no asymptomatic patients (grade 1$) ; 12$ patients had moderate effort dyspnoea only (grade 2) ; 25 had angina of effort or syncope in addition to effort dyspnoea (grade 3); and 64 of the 101 had congestive heart failure, paroxysmal nocturnal dyspnoea, and orthopnoea or angina decubitus (grade 4). Twenty-one of this group were in congestive heart failure, often very severe at the time of surgery despite intensive medical treatment.

Of the 42 patients with isolated aortic incompetence, two had moderate incompetence only and both have already been mentioned, namely, a 41-year-old woman with occlusion of the left coronary artery and angina decubitus and a 52-year-old man with essential hypertension. Both were in uncontrolled congestive heart failure, and valve replacement was performed to improve their symptomatic state. All other patients in this group had severe incompetence, including those with grade 2 symptoms. In the isolated aortic stenosis group, all 48 patients had severe stenosis on clinical grounds. In the multivalvular group every patient had been in heart failure, requiring a full medical regime for control. In six of the 11, the aortic valve lesion was moderate (five incompetent, one stenotic), the mitral valve disease being dominant.

The age of the patients is listed in Table II. The youngest was 14 and the oldest 68 years. There was a fairly even age distribution in the patients with aortic incompetence, 16 being under 30

T A B LE II

AGE INCIDFNCE

\begin{tabular}{|c|c|c|c|c|c|c|c|}
\hline & \multicolumn{7}{|c|}{ Age (years) } \\
\hline & $10-19$ & $20-29$ & $30-39$ & $40-49$ & $50-59$ & $60-69$ & Total \\
\hline $\begin{array}{l}\text { Aortic } \\
\text { incompetence } \\
\text { Aortic stenosis }\end{array}$ & $\begin{array}{l}5 \\
0\end{array}$ & $\begin{array}{r}11 \\
0\end{array}$ & $\begin{array}{r}12 \\
2\end{array}$ & $\begin{array}{r}7 \\
11\end{array}$ & $\begin{array}{l}10 \\
20\end{array}$ & $\begin{array}{r}7 \\
16\end{array}$ & $\begin{array}{l}52 \\
49\end{array}$ \\
\hline Total .. & 5 & 11 & 14 & 18 & 30 & 23 & 101 \\
\hline
\end{tabular}

years; whereas with aortic stenosis none was under 30 and two-thirds were 50 years or more.

The electrocardiogram revealed severe left ventricular hypertrophy in 85 patients, slight to moderate hypertrophy in 11 (five with incompetence and six with stenosis), and a complete bundle branch block in five (four involving the left and one the right branch).

The chest radiograph revealed a cardio-thoracic ratio of 50 or less, and therefore within the normal range in 24 patients (three with incompetence and 21 with stenosis) ; a ratio of 51 to 59 in 36 patients (16 with incompetence and 20 with stenosis); and of 60 to 75 in 41 patients (33 with incompetence and eight with stenosis).

Cardiac catheterization was not performed in any patient with isolated aortic incompetence, because diagnosis and assessment of severity were both possible on clinical grounds alone. The same was largely true in isolated stenosis, although in 17 such patients with severe stenosis, catheterization was considered necessary either because of unimpressive left ventricular hypertrophy or absence of valve calcification, or occasionally to exclude associated significant mitral valve disease. It was also undertaken in seven of the 11 multivalvular disease cases in an attempt to establish or quantitate the severity of the various lesions.

\section{TECHNIQUE}

Homograft aortic valves were collected usually within 12 hours of death, but longer periods were accepted when the body had been refrigerated and there was no infection. Most donors were under 50 years, but in a few instances valves from older donors were collected, if the cusps looked normal, for use in older patients. Sterile collection was insisted upon initially, but, because of its many difficulties, this has since been abandoned in favour of unsterile collection by the pathologist and sterilization within 12 hours using beta propiolactone. The valve was immersed in a nutrient medium, and, if not used within one week, was freeze-dried. Thus the valves used have had four different types of preparation: (1) taken sterile and stored in nutrient medium at $4^{\circ}$ C. (18 cases). Fifteen of these valves were inserted within one week of collection (the shortest interval being 18 hours), but in three early cases 16,24 , and 26 days had elapsed; (2) taken sterile and freezedried (32 cases). These valves were reconstituted immediately before use by immersion in distilled water for $30 \mathrm{~min}$. and then in isotonic saline; (3) sterilized with beta propiolactone and stored in nutrient medium (five cases, all used within eight days); (4) sterilized with beta propiolactone and freeze-dried (46 cases). This has now become the method of choice 
and has been in use since October 1963. Details of homograft valve sterilization and storage are given elsewhere (Barratt-Boyes, 1965a).

A median sternotomy incision was used except when the mitral valve also required attention, when the approach was through a modified right anterolateral incision (Barratt-Boyes, 1965b). Heart-lung by-pass flows varied from 2 to $2 \cdot 41 . / \mathrm{m}$./min., and the nasopharyngeal temperature was lowered to $30^{\circ} \mathrm{C}$. The machine was primed with a mixture of 2 parts of fresh heparinized blood to one part of $5 \%$ glucose containing $5 \mathrm{~g}$. of serum albumin per $100 \mathrm{ml}$. In six patients arterial return from the machine was into the ascending aorta rather than the external iliac artery, because of marked atheroma of the iliac arteries (three patients), an abdominal aortic aneurysm, an aortic coarctation, or in the remaining patient an aortic dissection from the iliac cannula site during the cooling phase of the perfusion. In 86 of the 101 patients, both coronary arteries were perfused continuously at $30^{\circ} \mathrm{C}$. through self-sealing coronary artery cannulae. In one patient aged 45 years the left coronary was completely occluded ; the right coronary was absent in two, and in one other was pinhole in size from luetic aortitis. In 10 patients with an average age of 65 years the right coronary ostia could be cannulated but not perfused, presumably because of atheromatous occlusion of the vessel.

The homograft valve was inserted using a circular suture line below the cusps and a scalloped suture line above, as previously described (Barratt-Boyes, 1964). In one patient, however, a single homograft cusp was all that was necessary. The size of homograft valve required was estimated by measuring the external diameter of the aortic root either visually or with callipers. Since many patients, particularly those with long-standing severe aortic incompetence, were found to have significant dilatation of the aortic root, it was at times necessary to use a valve which was too small for the host. This problem of matching the size of the homograft valve (selected and reconstituted during the cooling phase of the perfusion before the aorta is opened) to the host aortic root has more recently been completely overcome by excising as much as necessary of the non-coronary aortic sinus and aortic ring below the cusp. This important improvement in technique was not, however, used in the present series, and is described, along with other details, in a separate paper (Barratt-Boyes, 1965a).

In the four patients with frank aneurysms involving the whole of the intrapericardial portion of the ascending aorta, the aneurysm was completely excised and the aorta reconstituted by direct end-to-end anastomosis, the heart being pulled upwards to the distal aortic stump. Associated mitral valve surgery consisted of open mitral valvotomy in five patients, repair of a ruptured chorda in one, and complete mitral valve replacement in five (four Starr-Edwards ball valves and one mitral homograft).

Antibiotics were administered for two weeks postoperatively, and anticoagulants were not used except in the four patients with a Starr-Edwards mitral prosthesis, since it was felt that clot would not form on the homograft valve tissue or suture lines. Intermittent positive-pressure breathing was used twice only. Base was very rarely given post-operatively, and was not added to the priming blood. Mannitol was given during and after perfusion in patients with poor renal function early in the series as prophylaxis against renal failure but was rarely used later.

\section{RESULTS}

HOSPITAL MORTALITY AND MORBIDITY The hospital mortality includes deaths up to three months from operation and is listed in Table III. The mortality was $4.4 \%$ for the 90 patients with isolated aortic valve disease and $6 \%$ for the total series. It rose from $2 \cdot 4 \%$ in the 42 patients with aortic incom-

TABLE III

HOSPITAL MORTALITY

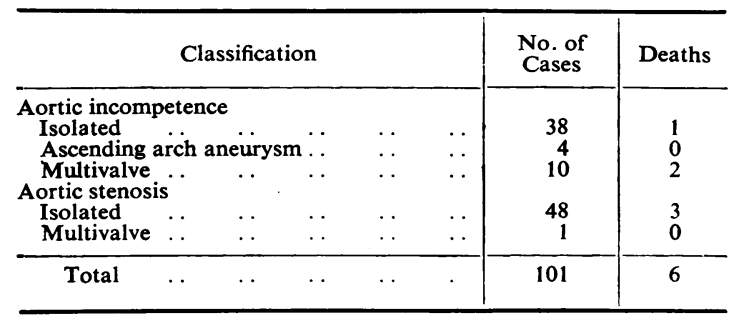

TABLE IV

HOSPITAL MORTALITY

\begin{tabular}{|c|c|c|c|c|c|c|}
\hline $\begin{array}{l}\text { Case } \\
\text { No }\end{array}$ & Age & Sex & Valve Lesion & $\begin{array}{c}\text { Symptoms } \\
\text { (grades) }\end{array}$ & Cause of Death & $\begin{array}{l}\text { Time after } \\
\text { Operation }\end{array}$ \\
\hline 1 & 20 & $\mathbf{M}$ & Aortic incompetence; mitral stenosis ; & 4 & Arrhythmia & 6 hours \\
\hline $\begin{array}{l}2 \\
3\end{array}$ & 32 & $\begin{array}{l}\mathbf{F} \\
\mathbf{F}\end{array}$ & $\begin{array}{l}\text { Aortic incompetence } \\
\text { Aortic incompetence; mitral stenosis; } \\
\text { mitral incompetence }\end{array}$ & $\begin{array}{l}2 \\
4\end{array}$ & $\begin{array}{l}\text { Bleeding } \\
\text { Myocardial infarction }\end{array}$ & $\begin{array}{l}6 \text { hours } \\
3 \text { hours }\end{array}$ \\
\hline 4 & 51 & $\mathbf{M}$ & Aortic stenosis & 3 & $\begin{array}{l}\text { Myocardial infarction } \\
\text { ('dissection' left coronary) }\end{array}$ & \\
\hline $\begin{array}{l}5 \\
6\end{array}$ & $\begin{array}{l}63 \\
63\end{array}$ & $\begin{array}{l}\mathbf{M} \\
\mathbf{M}\end{array}$ & $\begin{array}{l}\text { Aortic stenosis } \\
\text { Aortic stenosis }\end{array}$ & $\begin{array}{l}4 \\
4\end{array}$ & $\begin{array}{l}\text { Arrhythmia } \\
\text { Cerebral damage } \\
\text { (oxygenator fault) }\end{array}$ & $\begin{array}{l}\text { At operation } \\
3 \text { weeks }\end{array}$ \\
\hline
\end{tabular}


petence alone to $6 \%$ in the patients with aortic stenosis and $18 \%$ in the 11 patients who also required mitral valve surgery. All six patients concerned came to necropsy, and the causes of death are given in Table IV, arranged according to age. In case 1 the arrhythmia was probably secondary to anoxia and might have been prevented by intermittent positive pressure breathing. In all six patients perfusion of both coronary arteries was technically satisfactory, and in case 4 the so-called 'dissection' lay outside the media of the left coronary artery and its main branches and there was no intimal tear. The deaths bear surprisingly little relation to the severity of symptoms or to age, taking into account the fact that one patient aged 63 (case 6) died as the result of a technical fault in the heart-lung machine.

Significant hospital complications in the 95 surviving patients are noted in Table V. Complete

TABLE V

HOSPITAL MORBIDITY IN 95 SURVIVING PATIENTS

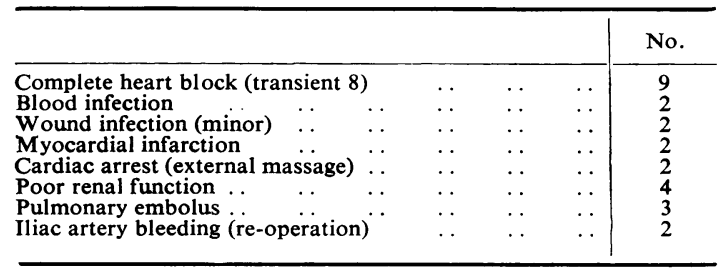

heart block occurred in nine patients. It was shortlived in seven, but in one it persisted for 20 days before returning to a stable sinus rhythm. In another patient, complete heart block has persisted, and in this man, aged 54, an implantable pacemaker unit has been inserted. Bacterial endocarditis occurred twice, and in both patients the infection, due to a staphylococcus in one and to Streptococcus faecalis in the other, was eradicated without evidence of damage to the homograft valve by a four-week course of antibiotics. Renal and pulmonary complications were minor, and no patient required re-operation because of bleeding from the chest. I.P.P.R. was used only twice, renal dialysis was never required, and no patient had persistent renal failure.

FOLLOW-UP STATUS With two exceptions, the 95 patients who left hospital have been reviewed recently, the duration of follow-up varying from four to 28 months. The majority have been examined periodically at Green Lane Hospital, and in the remainder information was available from cardiologists in other centres. Twenty-one of

\begin{tabular}{|c|c|c|c|c|}
\hline \multicolumn{5}{|c|}{$\begin{array}{c}\text { T A B LE V I } \\
\text { LATE MORTALITY }\end{array}$} \\
\hline Age & Sex & Clinical Features & Cause of Death & $\begin{array}{c}\text { Time } \\
\text { from } \\
\text { Surgery } \\
\text { (months) }\end{array}$ \\
\hline 66 & $\mathbf{M}$ & Aortic stenosis & Aortic incompetence & 6 \\
\hline 51 & $\mathrm{~F}$ & $\begin{array}{l}\text { Aortic incompetence, } \\
\text { diabetes }\end{array}$ & & $3 \frac{1}{2}$ \\
\hline 68 & $\mathbf{M}$ & $\begin{array}{l}\text { Aortic stenosis, com- } \\
\text { plete heart block, } \\
\text { coarctation of aorta } \\
\text { Aortic stenosis }\end{array}$ & Myocardial infarction & $4 \frac{1}{2}$ \\
\hline $\begin{array}{l}21 \\
29\end{array}$ & $\mathbf{M}$ & $\begin{array}{l}\text { Aortic incompetence } \\
\text { Aortic incompetence }\end{array}$ & & $\begin{array}{c}13 \\
5\end{array}$ \\
\hline $\begin{array}{l}45 \\
62\end{array}$ & $\underset{\mathrm{F}}{\mathrm{M}}$ & $\begin{array}{l}\text { Aortic incompetence } \\
\text { Aortic incompetence }\end{array}$ & Myocardial flbrosis & $3 \frac{1}{2}$ \\
\hline
\end{tabular}

the first 35 long-term survivors agreed to cardiac $\Phi$ catheterization, and this was performed 12 to 25 months after operation.

The late mortality is given in Table VI. There $\vec{\varphi}$ have been eight deaths three and a half to $13 \stackrel{\mathrm{F}}{\circ}$ months post-operatively, with necropsy in all cases. An aortic early diastolic murmur was present in five of these eight patients, but incompetence was minimal and unrelated to death except in one man aged 66 years. In this patient there was no diastolic $\frac{\varnothing}{\varnothing}$ murmur until a few days before death, when severe aortic incompetence appeared, leading to $\overline{0}$ acute left ventricular failure. Necropsy showed that this was due to detachment of two of the aortic leaflets at one commissure, at which point the cusps had undergone fibrinoid degeneration with a marked foreign body giant cell reaction. This valve had been obtained from a 63-year-old accident victim and was sterilized in beta propiolactone and freeze-dried before use. The detailed aortic valve pathology in this patient, and in the $\frac{3}{3}$ other seven where the aortic leaflets were well preserved, is contained in a separate report (Smith and Barratt-Boyes, 1965). Recent myocardialo infarction was the cause of death in three patients, two of whom had made excellent progress until o this time, but in one intermittent complete heart $N$ block was present before and after operation, and $N$ a moderate coarctation remained untreated. In the remaining four patients the only significant finding was widespread narrowing of small muscular coronary arteries by fibro-elastic intimal thickening in assocation with numerous localized areas of myocardial fibrosis. The youngest of these $\frac{0}{0}$ patients developed congestive heart failure six months after operation, with progressive cardio- $\frac{?}{\mathbb{D}}$ megaly. There was no aortic diastolic murmur or 2 other valve pathology. The second patient aged 292 


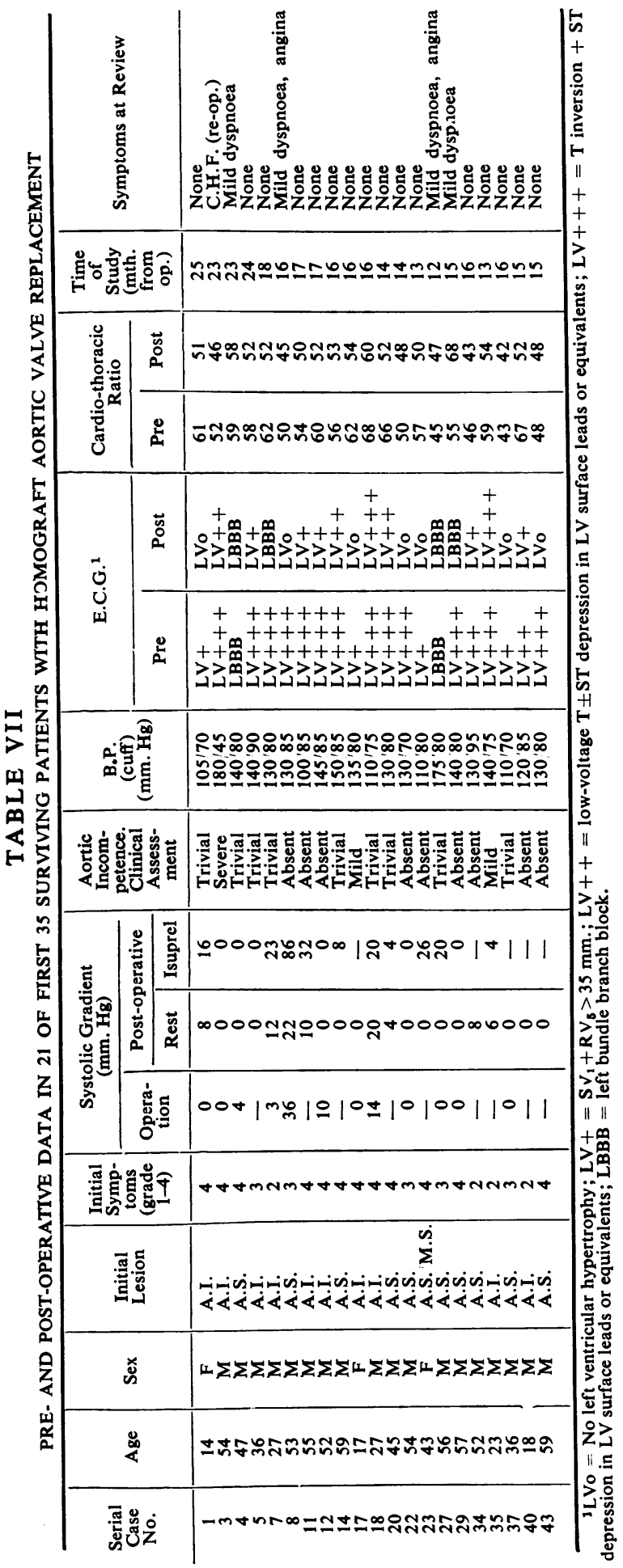


required re-operation at four months for recurrent aortic incompetence due to a peripheral leak between the homograft and the aortic wall. A second homograft was inserted without incident, but he died suddenly at home one month later when apparently well. The two older patients were also progressing well, with impressive reduction in heart size, at the time of sudden death. Some other necropsied hearts in this series have shown these microscopic features, but to a less marked degree. The detailed pathology in these cases is the subject of a separate report (Smith, 1965).

There has been striking symptomatic improvement in 82 of the remaining 85 traced patients. One 66-year-old man developed complete heart block six months post-operatively, and two patients had symptoms from residual severe aortic incompetence: both of these have had a second homograft valve inserted with complete symptomatic relief. Sixty-eight patients were symptom-free, five complained of slight effort dyspnoea, three had (in addition to dyspnoea) moderate effort angina which was less than before surgery and thought to be due to coronary artery disease, and three had palpitations from persistent ectopic beats as their only complaint. One patient with associated hypertension was greatly improved from his bedridden pre-operative state but still had effort dyspnoea and occasional paroxysmal nocturnal dyspnoea. A small cerebral embolus has been recognized once in a patient with a Starr-Edwards mitral valve in addition to a homograft aortic valve. The symptoms present in the 21 catheterized patients are included in Table VII.

The electrocardiogram has shown improvement in the degree of left ventricular hypertrophy in the great majority of patients, and where the follow-up extended for a year or more it had frequently returned to normal. Where little or no change had occurred this could sometimes be correlated with residual valve pathology (either aortic or mitral) or to a pre-existing conduction defect ; when these factors were absent there might be a persistent abnormality in the myocardium (Kelly, 1965). The electrocardiographic changes in the 21 catheterized patients are included in Table VII.

An analysis of the reduction in heart size on the routine chest radiograph one year or more after operation was possible in 43 patients, and for the 21 catheterized patients these data are included in Table VII. In the aortic incompetence group, 21 of 24 showed a reduction in heart size, while three, each with only minor cardiac enlargement before operation, showed little change. In the 19 patients with stenosis, seven with small hearts were unchanged and을 10 showed a reduction in size. In two patients, $\frac{\bar{F}}{\bar{n}}$ however, there was a post-operative increase in the $\frac{\text { क }}{\sigma}$ cardio-thoracic ratio related in one to the $\mathbb{Q}$ spontaneous appearance of complete heart block $\%$ six months after operation. In the other patient $\vec{\circ}$ (case 29, Table VII) the explanation was not clear ${ }_{-}$ although function studies indicated an abnormal $\vec{\omega}$ myocardium (Kelly, 1965).

Homograft valve incompetence has been $\overrightarrow{\vec{x}}$ assessed on clinical grounds as trivial when theĩ only finding was an aortic early diastolic murmur ;o as mild when there was, in addition, a slightly 8 jerky pulse but a pulse pressure within the normalo range; as moderate when there was also some은 widening of pulse pressure; and as severe whenthe peripheral pulse was bisferiens or water-o hammer in type. All patients with mild or moderate residual incompetence showed a radiological reduction in heart size, most showed some electrocardiographic resolution, and all claimed sympto- $\vec{\varphi}$ matic improvement, usually striking. In 10 of the 21 catheterized patients with aortic diastolic or murmurs (Table VII) indocyanine green was injec-o ted at varying levels in ascending and descending thoracic aortae, and the indicator dilution curveso were recorded from the left ventricle and the righto ear. A regurgitant fraction was not detected in anyळ of these patients, although on the clinical criteria $\overrightarrow{0}$ listed two (cases 17 and 35) had mild incom-3 petence. Angiocardiography was not used in this study, but in two subsequent patients with? moderate early diastolic murmurs classified clinically as trivial incompetence the amount of dye regurgitating into the left ventricle was alsox minimal.

The incidence of aortic incompetence at the time of review in the 93 traced patients is given in Table VIII. In the 44 patients with calcific aortic stenosis seven of the 15 with trivial residuaf incompetence developed the diastolic murmur $>$ from three to 12 months after discharge from hospital, but none has shown subsequent progression Nㅡㄴ

TABLE VIII

INCIDENCE OF AORTIC INCOMPETENCE IN 93 TRACED

\begin{tabular}{|c|c|c|c|}
\hline \multirow{2}{*}{$\begin{array}{l}\text { Post-operative } \\
\text { Aortic } \\
\text { Incompetence }\end{array}$} & \multicolumn{2}{|c|}{ Initial Aortic Lesion } & \multirow{2}{*}{ Total } \\
\hline & Stenosis & Incompetence & \\
\hline $\begin{array}{ll}\text { Absent } & . \\
\text { Trivial } & \ldots \\
\text { Mild } & . \\
\text { Moderate } \\
\text { Severe } \\
\end{array}$ & $\begin{array}{r}27 \\
15 \\
0 \\
1 \\
1\end{array}$ & $\begin{array}{r}18 \\
18 \\
6 \\
4 \\
3\end{array}$ & $\begin{array}{r}45 \\
33 \\
6 \\
5 \\
4\end{array}$ \\
\hline Total & 44 & 49 & 93 \\
\hline
\end{tabular}


in four patients an early diastolic murmur present at the time of discharge later disappeared. Of the stenotic group only two patients had significant residual incompetence $(4 \%)$. In one the leak was moderate but re-operation was undertaken because of disproportionate residual symptoms ; the homograft was partially detached peripherally and was replaced without incident. The second patient suddenly developed severe incompetence six months after operation and has already been detailed in the late mortality; the incompetence was due to a torn cusp.

In the 49 patients presenting for operation with aortic incompetence four of the 18 with a trivial residual leak developed the murmur after discharge from hospital and one murmur disappeared during the follow-up period. Residual incompetence was mild in six, moderate in four, and severe in three patients. In seven patients there was therefore a significant reflux through the homograft valve $(14 \%)$, although none in whom this was moderate has required re-operation, because symptoms were absent or minimal and cardiomegaly had regressed. However, the three patients with severe incompetence have all had a second homograft valve inserted without technical difficulty. In one of these patients the diastolic murmur first appeared at 18 months, and incompetence rapidly increased and was followed by congestive heart failure. At re-operation six months later one cusp had torn away from its upper point of attachment. This valve was collected sterile from a 22-year-old accident victim two hours after death and freezedried. The cusp may have been weak at the point of rupture, for it was noted to have very numerous fenestrations. The only abnormal microscopic finding in these cusps was a small area of fibrinoid degeneration adjacent to the tear without any cellular reaction. In the other two patients the incompetence was due to partial peripheral detachment of the homograft; one patient died one month after re-operation (see late mortality), but the other is well.

Homograft valve stenosis was not recognized clinically in any patient, although a mild to moderate ejection systolic murmur was usually present, often maximal towards the apex. This has been assessed in 21 patients 12 to 25 months after operation, when left ventricular pressures were obtained by a retrograde arterial approach from the right radial or brachial artery and the arterial pressure was monitored from a left brachial artery catheter. Left ventricular and brachial artery pressures were recorded simultaneously on equi-sensitive transducers while resting and after the infusion of isoprenaline. A venous catheter was passed to the right atrium or pulmonary artery for dye injection, and cardiac outputs were calculated using the Stuart Hamilton method. In 10 patients aortic incompetence was assessed by dye dilution curves as previously detailed. The systolic pressure gradient across the valve in these 21 patients is listed in Table VII.

There was no resting gradient in 13 patients, and in the remainder it reached a maximum of $22 \mathrm{~mm}$. $\mathrm{Hg}$; three of these patients had a gradient present at the end of operation. After isoprenaline administration a small gradient appeared in three, and in half the patients with a resting gradient there was a further increase, slight in three but reaching $86 \mathrm{~mm} . \mathrm{Hg}$ in one patient. The homograft valve in this man (case 8), the second to have this operation for calcific aortic stenosis, had been recognized to be too large for his rather small aorta, and this error in technique has been avoided subsequently. Despite the residual gradient, the electrocardiogram returned to normal within six months of operation although moderate angina of effort remained. The cardiac index was slightly below the normal range in four of the 21 patients (cases $4,8,11$, and 14), and in the 11 where it was also measured immediately after isoprenaline infusion it rose an average of $0.81 . / \mathrm{m}^{2}$ (range 0.2 to $1.51 . / \mathrm{m}^{2}$ ). The left ventricular end-diastolic pressure was raised in two patients (cases 4 and 29 ) to 14 and $16 \mathrm{~mm}$. $\mathrm{Hg}$ respectively, and in both there was persistent cardiomegaly (Table VII) and poor myocardial function (Kelly, 1965).

Clinically significant mitral incompetence was present at the time of review in four patients, mild in three and moderate in one. Only one of these patients had had the mitral valve operated upon, the remaining 10 in the multivalvular group having no significant residual mitral lesion.

The final assessment in the 101 patients, after the second operation performed in four for residual aortic incompetence, is given in Table IX. In 79 of the total the result was considered most gratifying, although it was classified as good rather than excellent in the 28 patients with trivial aortic incompetence; it was satisfactory in the six with mild incompetence, the one patient known to have mild stenosis, and the two patients known to have a raised left ventricular end-diastolic pressure. In six patients the result was considered less than satisfactory because of moderate aortic incompetence in four and complete heart block in two. One of these patients, with a surgically produced heart block which is well controlled with an implanted pacemaker, also had moderate mitral 
TABLE IX

HOMOGRAFT AORTIC VALVE REPLACEMENT: FINAL ASSESSMENT OF RESULT

\begin{tabular}{|c|c|c|c|c|c|c|}
\hline \multicolumn{5}{|c|}{ Result } & \multicolumn{2}{|c|}{ No. of Cases } \\
\hline $\begin{array}{l}\text { Hospital deaths } \\
\text { Late deaths ... }\end{array}$ & $\begin{array}{l}\ldots \\
\cdots\end{array}$ & $\because$. & $\begin{array}{l}\cdots \\
\cdots\end{array}$ & $\begin{array}{l}\cdots \\
\cdots\end{array}$ & $\begin{array}{l}6 \\
8\end{array}$ & 14 \\
\hline $\begin{array}{ll}\text { Excellent } & \ldots \\
\text { Good } & \ldots \\
\text { Satisfactory } & \ldots\end{array}$ & $\begin{array}{l}\cdots \\
\cdots \\
\cdots\end{array}$ & $\begin{array}{l}\ldots \\
\cdots \\
\cdots\end{array}$ & $\begin{array}{l}. \\
\cdots \\
\cdots\end{array}$ & $\begin{array}{l}\ldots \\
\cdots \\
\cdots\end{array}$ & $\begin{array}{r}42 \\
28 \\
9\end{array}$ & 79 \\
\hline $\begin{array}{l}\text { Less than satisfactc } \\
\text { Untraced }\end{array}$ & $\begin{array}{l}\text { ory } \\
\ldots\end{array}$ & $\begin{array}{l}\cdots \\
\cdots\end{array}$ & 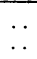 & $\begin{array}{l}\ldots \\
\cdots\end{array}$ & & $\begin{array}{l}6 \\
2\end{array}$ \\
\hline Total .. & $\ldots$ & $\ldots$ & $\ldots$ & $\ldots$ & & 101 \\
\hline
\end{tabular}

incompetence, and the other (in whom the heart block appeared spontaneously six months after operation) was the only patient with disabling symptoms. This man is awaiting pacemaker insertion.

\section{DISCUSSION}

The results achieved with this new technique, in a group consisting very largely of poor risk patients with advanced disease, indicate that it is a safe and satisfactory operation. The hospital mortality of $4.4 \%$ in patients with isolated aortic valve disease compares very favourably with the best results that have been reported with the StarrEdwards ball valve (McGoon, Ellis, and Kirklin, 1965), and there seems little doubt that when more confidence has been gained in the long-term behaviour of the homograft valve and when surgery can therefore be offered to better risk patients it will fall to even lower levels. The operative risk appears to be lower in isolated aortic incompetence $(2.4 \%)$ than in calcific aortic stenosis $(6 \%)$, perhaps because the former patients tend to be younger. Apart from this questionable difference, the hospital mortality does not appear to relate closely to other factors or to the severity of symptoms. Thus only one of 14 patients with fairly clear evidence pre-operatively of myocardial infarction died, and there was also only one death among the 21 patients in frank congestive heart failure at the time of operation; and this in a patient with associated severe mitral and tricuspid valve disease. Associated valvular disease was the only factor closely related to mortality, which rose, in the 11 patients in this group, to $18 \%$. In view of these operative results there is every justification in recommending operation in all patients with severe aortic valve disease despite the presence of such factors as age, coronary artery disease, persistent congestive heart failure, reduced renal function, ascending aortic arch aneurysm, and mitral valve disease of a severity demanding concomitant relief.음 With the information obtained from this follow $\frac{\bar{c}}{\frac{1}{5}}$ up study of 93 patients for a maximum period of 28 months it appears that the homograft valven continues to function well provided it is accurately inserted and is not too small for the host. In contrast to the ball-valve prosthesis, it has been $\vec{\omega}$ entirely free of the problems of embolization, infection, and haemolysis, and anticoagulants are not required. The data also indicate that in contrast to the Starr-Edwards ball valve (Bristowio McCord, Starr, Ritzmann, and Griswold, 1964)s there is usually no gradient across a homografter valve even when the cardiac output is increased? with isoprenaline, and pathological examinationof homograft cusps two years after insertion does not show any thickening or calcification.

The one matter of some concern is the incidences of post-operative incompetence. An aortic early diastolic murmur was present in 48 patients $(52 \%) ; \vec{\square}$ and in this group 15 had significant residualo incompetence, classified as mild in six patients: moderate in five, and severe in four. It is signifi-o cant that a residual leak through the valve was fars more frequent in patients operated on for aortico incompetence, a difference that can only be due toळ the frequency of a dilated aortic ring in such patients and the fact that the homograft valve in $\overrightarrow{\overrightarrow{0}}$ these circumstances was sometimes too small 3 There are four apparent causes of a post-operative? aortic diastolic murmur with or without significan? incompetence: (1) Imperfect approximation of the three cusps due to slight twisting of the graft or slight cusp redundancy. The diastolic murmur wilk be trivial and if the cusps alter slightly in shape? the murmur may disappear, a feature noted in five patients. (2) The homograft valve may become partially detached despite the double suture line technique, giving rise to a peripheral leak of vary-은 ing magnitude. This was the known cause of incompetence in three of the patients who requirede. re-operation. It should be completely avoidables provided suturing is accurate and the valve is of adequate size. (3) The homograft valve is toon small for the host, so that the three leaflets do not coapt adequately and a central leak occurs. This is probably the commonest cause in this series because its importance was not fullye appreciated until quite recently. When this is the basis of the incompetence it may be expected to increase gradually; it is perhaps surprising tha there is no convincing evidence that this has ye? occurred, although it may be the explanation for the later appearance of trivial incompetence in 
11 patients. Fortunately this major difficulty of obtaining a correct fit between homograft valve and host aortic root, so that the cusps are moderately redundant, can now be overcome by tailoring the aortic root down to fit the valve (Barratt-Boyes, 1965a). Since this modification in technique has been used there has been a striking reduction in the frequency of aortic diastolic murmurs and no patient has had significant aortic incompetence at the time of discharge from hospital. (4) Homograft cusp failure has occurred twice, six months and 18 months after operation. In both patients the valve was completely competent until this time, and the incompetence was sudden in appearance, severe, and due to disruption of one or two of the cusps at their uppermost point of attachment to the aortic wall. In the patient who died at six months the affected cusps showed a marked cellular reaction surrounding a localized area of fibrinoid necrosis. A similar histological change has been found in one other competent valve examined four months after insertion in a patient who died of myocardial infarction; and in both these cases the valve had been sterilized in beta propiolactone prior to freeze-drying. In the second patient the valve was replaced two years after the first operation, and the torn cusp again showed a localized area of fibrinoid degeneration but without cellular reaction. The cusps in this valve, which was collected sterile and freeze-dried, were noted to have numerous fenestrations at the time of insertion and may have been weakened from this cause.

A total of 12 homograft valves have now been examined microscopically for varying periods from three to 24 months after insertion: with the exceptions just noted, all have shown remarkable preservation of the collagenous and elastic tissue (Barratt-Boyes, 1964 ; Smith and Barratt-Boyes, 1965). This means that there is no good evidence from our material that post-operative incompetence is related to the use of beta propiolactone or to freeze-drying, and for this reason the most convenient method of valve preparation (unsterile collection with beta propiolactone sterilization and subsequent freeze-drying) has become routine (Barratt-Boyes, 1965a).

The only other complication, in addition to aortic incompetence, which requires mention is complete heart block. Any technique in which suturing is required below aortic cusp level endangers the bundle of $\mathrm{His}$ where it penetrates the right fibrous trigone beneath the non-coronary aortic cusp and passes forwards immediately below the membranous ventricular septum. Fortunately, in these first 101 patients, surgically induced permanent heart block has occurred once only and theoretically should be avoidable. When part or all of the non-coronary aortic sinus region must be removed to narrow down the aortic ring additional care must of course be exercised.

Re-operation has been undertaken in four patients in this series with residual aortic incompetence and it has not proved technically difficult to insert a second homograft valve. In two, the non-coronary sinus region and adjacent aortic ring were excised at this second operation to reduce the diameter of the outflow, and in all cases the aortic incompetence was successfully corrected. Three of these patients are now symptom-free, but one died unexpectedly one month later.

There have been eight late deaths in this series of patients ; only one of these was due to recurrent aortic incompetence, and in the remaining seven death was apparently secondary to coronary artery disease. Among these, in three there was an atheromatous occlusion of a large coronary artery with recent myocardial infarction, but in four the only abnormality was a diffuse narrowing of the small coronary arteries by fibro-elastic intimal thickening associated with numerous areas of myocardial fibrosis (Barratt-Boyes, 1964 ; Smith, 1965). These four patients all had longstanding severe aortic incompetence with cardiomegaly before operation. Similar changes have been found occasionally in association with other valve lesions, chiefly aortic stenosis, and the evidence suggests that they are most common and severe in advanced aortic incompetence. They may be an explanation not only of late deaths after correction of the valve lesion but also of persistent cardiomegaly and failure of resolution of electrocardiographic changes. There does not seem to be any evidence that the fibro-elastic intimal thickening is secondary to the operation, in particular the coronary artery perfusion technique, for identical changes of considerable duration have been found in patients with severe aortic incompetence who died without surgery and also among the early post-operative deaths which occurred within hours or days of perfusion. It may also be significant that in only one of these seven patients was there any technical difficulty with coronary artery perfusion.

Myocardial function studies have been undertaken post-operatively in 20 patients in this series (Kelly, 1965). Although these are not reported here, it must be noted that a significant number of patients without residual valve defects have been 
shown to have reduced myocardial function ; this correlates well with poor resolution of left ventricular hypertrophy in the electrocardiogram, persistent cardiac enlargement on the chest radiograph, and, when present, with an elevated left ventricular end-diastolic pressure. These findings and the disturbing histological features noted above may indicate that surgical correction of a severe aortic valve lesion should be undertaken earlier than has been the practice to date, particularly when severe aortic incompetence is present.

In one patient in this series partial aortic valve replacement, using a single homograft cusp, was all that was required to correct aortic incompetence secondary to bacterial endocarditis. Although total valve replacement is usually needed in these circumstances, single cusp replacement is the treatment of choice in severe aortic incompetence with ventricular septal defect, and the use of a homograft cusp should be seriously considered in such patients.

\section{SUMMARY AND CONCLUSIONS}

The first two years' experience with homograft valve replacement at Green Lane Hospital has been reviewed. In most cases the homograft valve was sterilized with beta propiolactone and preserved by freeze-drying.

The series consists of 101 patients, and the follow-up extends from four to 28 months. The great majority of patients had advanced disease, often with additional abnormalities, including four with ascending aortic arch aneurysm and 11 patients requiring simultaneous mitral valve surgery. Twenty-one patients were in congestive heart failure at operation, and 53 were in the sixth and seventh decades.

The hospital mortality was $6 \%$, rising from $2.4 \%$ in isolated aortic incompetence to $6 \%$ in isolated aortic stenosis and to $18 \%$ in multivalvular disease. Permanent complete heart block was produced at operation in one patient.

Follow up was complete in 93 of the 95 surviving patients, and cardiac catheterization was performed in 21 patients. In the catheterized group, only one patient had significant residual stenosis, and in most there was no gradient across the valve.
An aortic diastolic murmur was present in 48 , and in 15 of these residual aortic incom- $\frac{}{\infty}$

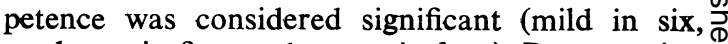
moderate in five, and severe in four). Re-operation $\triangle$ was successfully undertaken in some of this group. The incompetence was shown to be due to tearing $\vec{O}$ of homograft cusps in two patients and to a peri- pheral leak in three, and it was probably caused $\vec{\omega}$ by overstretching of too small a valve in most of the remainder.

There were eight late deaths, one due to recurrent aortic incompetence and seven to coronary artery disease, the nature of which was $\frac{t}{0}$ unusual in four patients.

With one exception, all 85 traced long-term $\stackrel{\circ}{\supset}$ survivors were either free of symptoms or had shown marked symptomatic improvement, and in $\bar{O}$ 79 the result was considered to be very satisfactory.

In conclusion, it appears from this analysis that the homograft aortic valve may, at this stage in $\vec{\theta}$ development, be the replacement of choice in aortic valve disease, for it has not resulted in. stenosis or embolization or infection, and longterm anticoagulants are not required. Although rupture of homograft cusps has occurred twice as a late complication, emphasizing that caution is still required in assessing the long-term results and $\varrho$ the method of valve preparation, it appears that $\overrightarrow{0}$ residual aortic incompetence, which has proved to 3 be the only significant complication apart from the rare production of complete heart block, is? almost entirely the result of errors in technique and should be largely avoidable in future.

\section{REFERENCES}

Barratt-Boyes, B. G. (1964). Homograft aortic valve replacement in aortic incompetence and stenosis. Thorax, 19, 131.

(1965a). A method for preparing and inserting a homograft aortic valve. Brit. J. Surg. In press.

(1965b). Surgical results in multivalvular heart disease. N.Z.음 med. J., Suppl. In press.

Bristow, J. D., McCord, C. W., Starr, A., Ritzmann, L. W., and Griswold, H. E. (1964). Clinical and hemodynamic results of aortic valvular replacement with a ball-valve prosthesis. Circulation, 29, Suppl. 1, p. 36.

Kelly, D. N. (1965). An assessment of myocardial function following homograft aortic valve replacement. N.Z. med.J., Suppl. In press .N

McGoon, D. C., Ellis, F. H. Jr., and Kirklin, J. W. (1965). LateO results of operation for acquired aortic valve disease. Circulation, $N$ 31, Suppl. 1, p. 108.

Smith, Judith C. (1965). Obstructive disease of small coronary arteries in association with aortic valve disease. In preparation and Barratt-Boyes, B. G. (1965). The pathology of humanc homograft aortic valves. In preparation. 